University of Nebraska - Lincoln

DigitalCommons@University of Nebraska - Lincoln

$9-2019$

\title{
Promoting Change in Common Tern (Sterna hirundo) Nest Site Selection to Minimize Construction Related Disturbance.
}

Peter C. McGowan

Jeffery D. Sullivan

Carl R. Callahan

William Schultz

Jennifer L. Wall

See next page for additional authors

Follow this and additional works at: https://digitalcommons.unl.edu/usfwspubs

This Article is brought to you for free and open access by the US Fish \& Wildlife Service at

DigitalCommons@University of Nebraska - Lincoln. It has been accepted for inclusion in US Fish \& Wildlife Publications by an authorized administrator of DigitalCommons@University of Nebraska - Lincoln. 
Authors

Peter C. McGowan, Jeffery D. Sullivan, Carl R. Callahan, William Schultz, Jennifer L. Wall, and Diann J. Prosser 


\section{Promoting Change in Common Tern (Sterna hirundo) Nest Site Selection to Minimize Construction Related Disturbance.}

Peter C. McGowan (corresponding author: U.S. Fish and Wildlife Service, Chesapeake Bay Field Office, 177 Admiral Cochrane Drive, Annapolis, Maryland, 21401, peter_c_ mcgowan@fws.gov), Jeffery D. Sullivan (Natural Systems Analysts, Winter Park, Florida), Carl R. Callahan (U.S. Fish and Wildlife Service, Chesapeake Bay Field Office, Annapolis, Maryland), William Schultz (U.S. Fish and Wildlife Service, Chesapeake Bay Field Office, Annapolis, Maryland), Jennifer L. Wall (Chesapeake Conservation Corps, Chesapeake Bay Trust, Annapolis, MD), and Diann J. Prosser (Patuxent Wildlife Research Center, U.S. Geological Survey, Beltsville, Maryland).

ue to the many challenges facing waterbird populations (Jia et al. 2018, Wetlands International 2018), it has become common practice to limit disturbance to breeding colonies whenever possible to maximize reproductive success. While this may require often unpopular

Ecological Restoration Vol. 37, No. 3, 2019

ISSN 1522-4740 E-ISSN 1543-4079

○2019 by the Board of Regents of the University of Wisconsin System. 


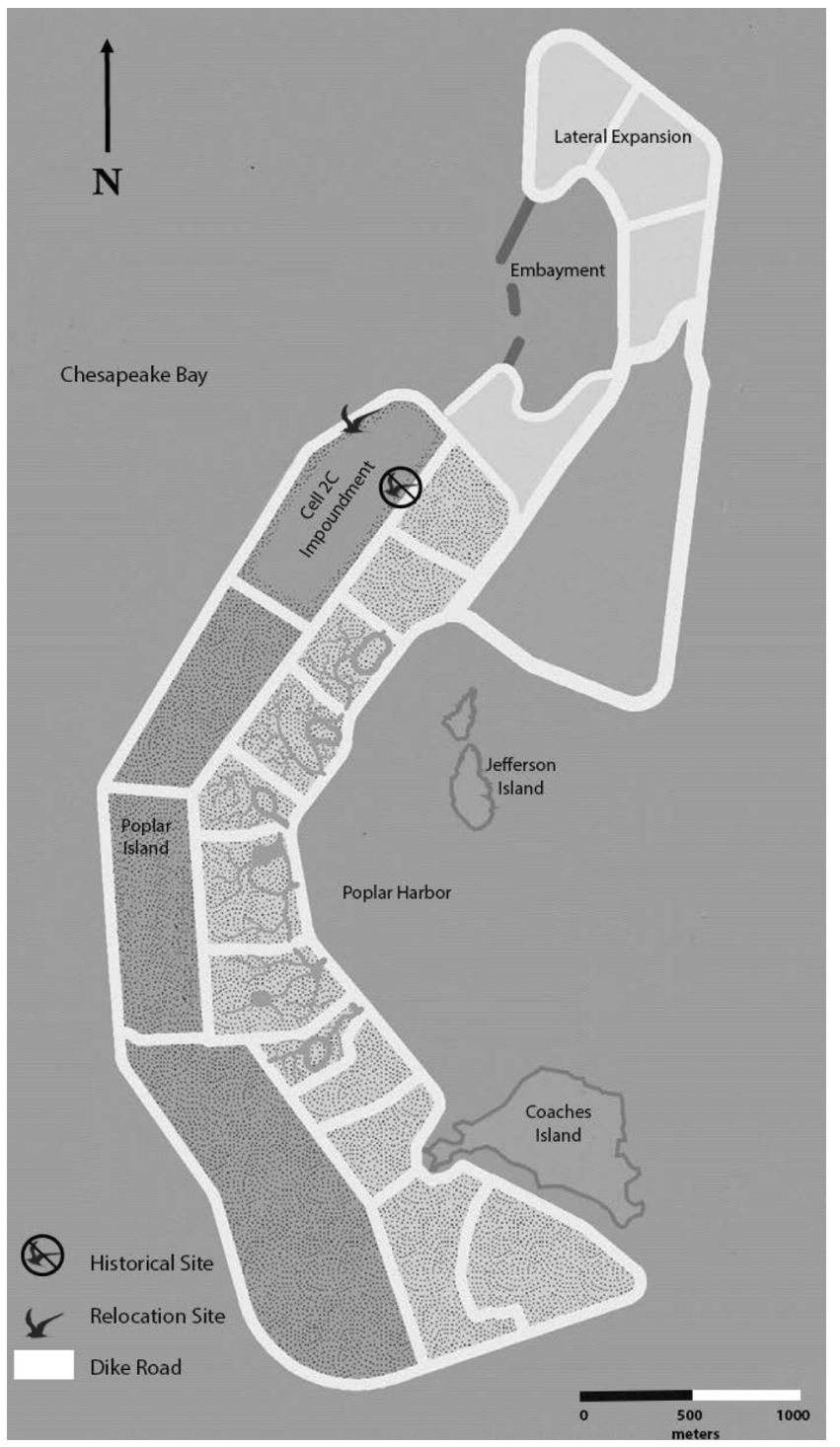

Figure 1. Map of Poplar Island showing areas of lateral expansion (the area of construction activity), historical Sterna hirundo colony nesting site, and colony relocation site (image courtesy of U.S Army Corps of Engineers).

management techniques including beach closures (Jorgensen et al. 2015, Mayo et al. 2015) and predator removal (Neuman et al. 2004, Stocking et al. 2017), such actions are sometimes necessary for the success of the colony. However, there are instances when eliminating disturbance is not possible and birds must be attracted to a new site. A common method for attracting waterbirds to a desired location is paired auditory and visual attractants such as decoys and conspecific calls, a highly effective approach for terns (Jeffries and Brunton 2001, Roby et al. 2002, Arnold et al. 2011), murres (Sawyer and Fogle 2013), and other colonial nesting waterbirds (see Friesen et al. 2017 for a review).

While attracting breeding populations to desired locations is an important step in colony relocation, managers must also ensure that individuals do not nest at the historical nesting site. One approach is to reduce the quality or quantity of breeding habitat at the historical colony and create or improve habitat at a desired location (Roby et al. 2002, Hartman et al. 2018). However, this jeopardizes the colony if the new site is not adopted. Another option is the use of overhead lines and flagging. This approach is commonly used to deter nuisance species (Pochop et al. 1990) but has also been successful for preventing nesting of various tern species (Roby et al. 2002, Marcus et al. 2007).

The goal of our study was to evaluate the use of a paired attractant and deterrent to facilitate the relocation of a Sterna hirundo (Common Tern) breeding colony from its historical nesting location in the face of extensive disturbance. We hypothesized that the paired use of attractants placed in suitable breeding habitat and deterrents covering the entirety of the historical nesting colony would result in complete relocation of the breeding population to the new target area.

The Paul S. Sarbanes Ecosystem Restoration Project at Poplar Island (Poplar Island), located in Talbot County, Maryland $\left(38^{\circ} 46^{\prime} 01^{\prime \prime} \mathrm{N}, 76^{\circ} 22^{\prime} 54^{\prime \prime} \mathrm{W}\right)$, is a U.S. Army Corps of Engineers (USACE) and Maryland Port Administration (MPA) beneficial use of dredged material project (USACE 2005). Poplar Island serves as the largest of only two $S$. hirundo nesting sites within the Maryland portion of the Chesapeake Bay. The largest S. hirundo colony present on Poplar Island is traditionally located at the north end of the island within the northeast corner of a dredge containment unit (elevation: eight meters above sea level, Figure 1). The historical nesting site was a narrow linear parcel of land encompassing approximately 0.70 ha. The nesting substrate was composed of a sand/clay/shell mixture, interspersed with vegetation that grows to increasing density as the breeding season progresses (May through August). Similar habitat is found in abundance throughout this area of the island.

At times, on-site conflicts arise between avian use and construction activities. For example, during the 2017 and 2018 S. hirundo nesting seasons ongoing construction activity increased heavy equipment and foot traffic near the historical nesting site (Figure 1). However, continuation of the project was necessary to avoid significant complications and delayed habitat development. Due to the negative impacts disturbance would have on nesting terns and the need to continue construction, the decision was made to promote nesting approximately $200 \mathrm{~m}$ northwest of the historical site. Nesting substrate within the relocation site was sandier than the historical site due to the recent deposition of fresh sand used for dike construction, but the area was comparable in size.

Sterna hirundo were deterred from using the historical site during the 2017 and 2018 nesting seasons by placing perpendicular, diagonal, and parallel overhead lines (mason line). In late April 2017 (concurrent with the arrival 


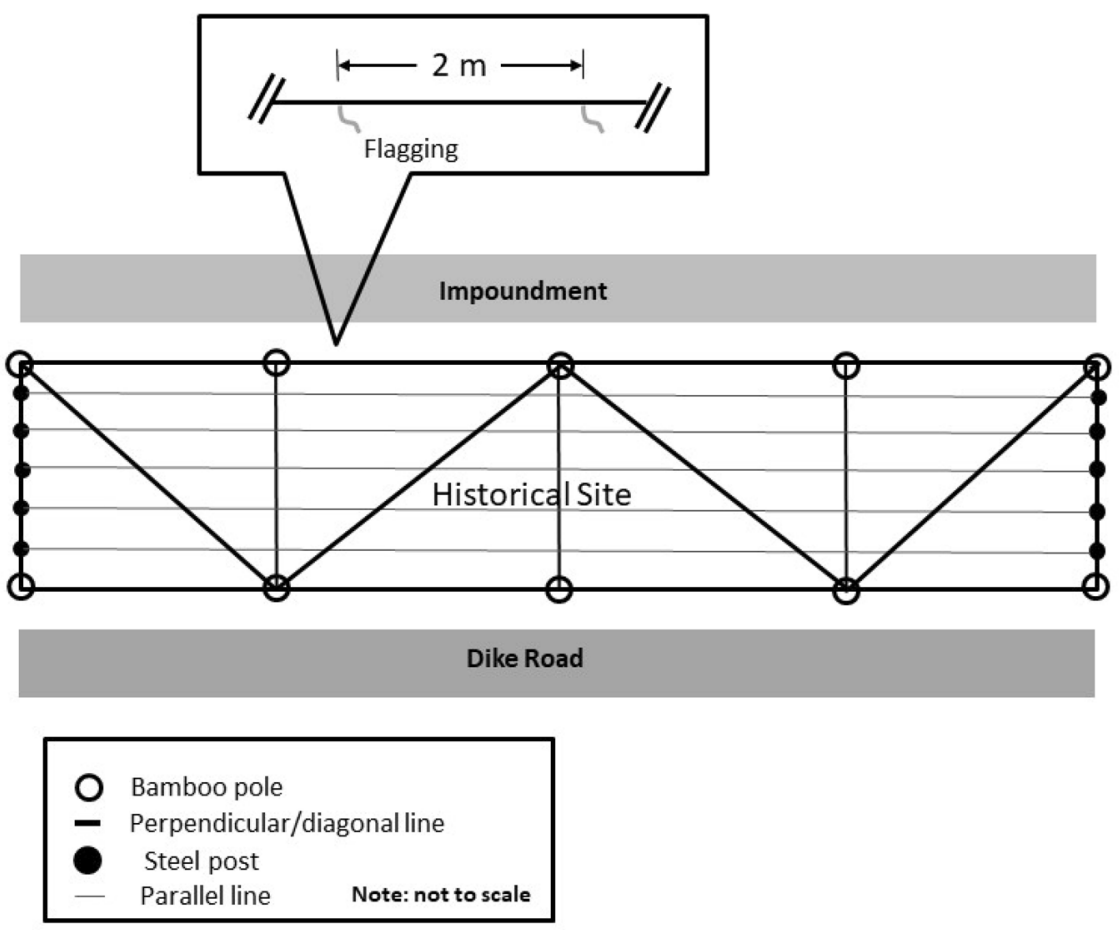

Figure 2. Diagram showing arrangement of overhead lines established within the historical Sterna hirundo colony at Poplar Island. Steel post and parallel lines were put in place two days after bamboo poles and perpendicular/ diagonal lines were set up.

of terns), the outer boundary of the nesting site was staked with 3-meter $(\mathrm{m})$ long bamboo poles placed approximately 10-m apart to which mason line was attached at a height of approximately $1.5-\mathrm{m}$ above the ground. Mason line was then attached to bamboo poles in a zig zag pattern (Figure 2). Strips of surveyors' flagging tape, approximately $45-\mathrm{cm}$ in length, were attached to the lines at approximately 2-m intervals.

Although the above effort was successful in deterring most terns from landing within the exclusion area, a few pairs established early nests in 2017. To ensure complete tern deterrence, overhead parallel lines were set up two days after the first set of lines were established (Figure 2). Overhead parallel lines were placed approximately $1-\mathrm{m}$ apart the entire length of the nesting site and were located $1.5-\mathrm{m}$ above the ground. The ends of each line were tied to $2-\mathrm{m}$ steel posts. Surveyors' flagging tape was attached to the lines in a similar manner as described above. This revised method was used exclusively in 2018 following the same timeline as 2017.

Upon discovery, eggs from nests established prior to the placement of overhead parallel lines in 2017 were individually marked and placed in an incubator (Little Giant 9300, Miller Manufacturing Company, Glencoe, MN) set at $37.5^{\circ} \mathrm{C}$ (Rattner et al. 2011). Approximately 60 minutes after collection, eggs were fostered to early stage nests (one to two eggs present) in the relocation site. Each foster nest was individually marked and monitored two to three times a week during the incubation and hatching period as part of routine colony monitoring. Colony monitoring, conducted across both years from early May through late August, consisted of researchers walking through the colony identifying and marking new nests, recording the number of eggs in every nest, and capturing chicks for banding with plastic field-readable bands and metal USGS bands. The notes taken on nest status during these surveys determined the hatching success of both foster eggs and other eggs within the foster nests. If an egg was no longer in the nest 19-31 days after the clutch initiation date, it was considered likely to have hatched unless 1 ) signs of predation were present (in which case it was considered failed), or 2) a chick was captured or observed (in which case it was considered confirmed hatched). Eggs gone from the nest prior to 19 days or remaining after 31 days of clutch initiation, or with field signs indicating non-viability (non-pipping related holes, lack of parental tending) were considered not to have hatched. While reported incubation length varies from 21-29 days (Hays and LeCroy 1971, Burger and Gochfeld 1991, Arnold et al. 2006), we used a slightly wider range as nests were not monitored daily.

Relocation efforts involved the use of social attractants that included both conspecific audio (digital calls) and visual attractants (decoys) placed within the relocation site one week before deterrents were setup in the historical nesting site (Leumas 2010). Four times a day for 20 min intervals $(0700 ; 1100 ; 1400$; and 1800 hours), a solar powered digital call box was programmed to play a mix of Sterna antillarum (Least Tern) and S. hirundo calls sourced from previous onsite recordings and the Cornell Lab of Ornithology. Three dozen acrylic resin Sterna dougallii (Roseate Tern) tern decoys hand-painted to resemble $S$. hirundo were randomly placed near the call box and surrounding area. There was no difference in attraction approach across seasons. Cooperators agreed that this 
Table 1. The hatching success of Sterna hirundo eggs in nests which hosted foster eggs during 2017. Eggs were fostered into nests when only 1-2 eggs were present, and the number of eggs reported includes the foster egg. Eggs were considered likely to have hatched if the egg was no longer present within the nest 19-31 days after clutch initiation, and were considered confirmed hatched if a chick was either captured or observed at the nest. Eggs were considered not to have hatched if the egg was no longer observed in the nest $<19$ days or $>\mathbf{3 1}$ days after clutch initiation, or if observation indicated the egg was no longer viable (i.e., holes in the egg or obvious lack of parental care).

\begin{tabular}{ccccc}
\hline Nest & Eggs & $\begin{array}{c}\text { Confirmed } \\
\text { Hatched }\end{array}$ & $\begin{array}{c}\text { Likely } \\
\text { Hatched }\end{array}$ & Did not hatch \\
\hline 1 & 4 & 2 & 2 & 0 \\
2 & 4 & 3 & 0 & 1 \\
3 & 4 & 3 & 1 & 0 \\
4 & 4 & 0 & 0 & 0 \\
5 & 3 & 3 & 0 & 0 \\
6 & 4 & 3 & 1 & 0 \\
7 & 3 & 3 & 0 & 0 \\
8 & 3 & 0 & 0 & 0 \\
9 & 3 & 3 & 0 & 0 \\
10 & 3 & 1 & 2 & 0 \\
11 & 3 & 3 & 0 & 0 \\
12 & 3 & 1 & 0 & 2 \\
13 & 4 & 1 & 2 & 1 \\
\hline
\end{tabular}

approach would be considered a success if complete relocation of the colony from the historical location to the new target location could be achieved. No statistical analyses were required.

While initial deterrent efforts in 2017 were mostly successful, nine $S$. hirundo pairs did establish nests within the exclusion area prior to the addition of the parallel overhead lines. These early nests contained $\leq$ two eggs each for a total of 13 eggs that were fostered to 13 separate nests. Monitoring indicated that 11 of $13(85 \%)$ foster eggs hatched successfully, while two nests (each containing one foster egg) were washed out in a storm. The presence of foster eggs appeared to have little impact on the hatching success of other eggs within the nest, as most eggs were either confirmed to have hatched or were likely to have hatched (Table 1). The addition of parallel overhead lines a few days after establishing the first set of overhead lines resulted in complete deterrence within the historical nest site, with no new nesting attempts observed. The use of the modified deterrent design in 2018 resulted in no nesting attempts within the historical colony.

The establishment of S. hirundo pairs nesting in the relocation site occurred within a few days of the deployment of social attractants each season. Breeding activity did not appear to be reduced at this new location. In 2017 researchers observed 182 active nests prior to the establishment of an additional 58 nests late in the season and captured and banded a then record number of $S$. hirundo chicks (257). In 2018 researchers documented 303 nests prior to the establishment of an additional 111 nests late in the season and banded $425 \mathrm{~S}$. hirundo chicks.

Our results describe the successful pairing of attractants and deterrents to lure nesting $S$. hirundo to a new location. Ceasing construction related activities until after the nesting season would have imposed a major burden to the project and delayed completion of important future habitat. Relocation of the breeding colony allowed for human activity and an important waterbird breeding population to coexist. However, these findings should not be used to justify colony relocation in all scenarios as long-term impacts of relocation on colony productivity and sustainability have yet to be examined. Instead, these data should be used only to inform managers exploring all options.

The success of this approach was consistent with results for Sterna caspia (Caspian Tern, Roby et al. 2002) and S. antillarum (Marcus et al. 2007). However, given the local conservation status of $S$. hirundo, having species specific results provides much needed information for managers. Unfortunately, a lack of controls and replications does not allow us to conclude if the observed relocation was the result of deterrents or attractants independently, or a response to their cumulative influence. Setting up multiple relocation cells with various treatments and controls was not feasible due to the importance of successfully relocating the colony. Our results were also confounded by the initiation of construction, though we doubt construction related disturbance alone would have dissuaded nesting attempts as some birds initiated nests within the historical colony while light construction was ongoing (prior to addition of parallel overhead lines and increase in construction intensity). Similarly, while terns may have been drawn to the relocation site due to the improved habitat from sand addition, this seems unlikely due to the availability of sandy habitat throughout Poplar Island.

While the ability to draw birds away from their historical colony to a new location is significant, such practices may not be viable if they result in lowered reproduction. Fortunately, data from associated monitoring efforts suggests that the fledging success of hatched chicks remained relatively constant following colony relocation (Prosser 2017). This comparable fledging success combined with the increased number of breeding pairs and hatched chicks within this colony suggests colony relocation had minimal negative impacts on reproduction. These results are contradictory to the findings of Roby et al. (2002) which saw slight declines in productivity after the relocation of a S. caspia colony. However, Roby et al. (2002) relocated the colony $\sim 30 \mathrm{~km}$ and reported significant dietary changes whereas we relocated less than $0.25 \mathrm{~km}$ and would expect no differences in available food stocks. 
While our results demonstrate the effectiveness of colony relocation to avoid certain high disturbance situations, we cannot make such strong conclusions about fostering eggs. Though the observed hatching rates suggests little if any negative effects were experienced by fostered eggs or the other eggs within the nest, this does not guarantee that chicks did not have diminished fledging success or reduced fitness (Berggren 2006). However, using this technique to facilitate hatching of a small number of individuals may be viable.

\section{Acknowledgements}

Egg fostering, along with deterrent and attractant placement, was led by the U.S. Fish and Wildlife Service (Service) in accordance with appropriate federal and state permits from the Service's Region 5 Migratory Bird Office and the Maryland Department of Natural Resources. All data related to nest surveys and chick marking were collected in accordance with protocol approved by the Patuxent Wildlife Research Center Animal Care and Use Committee. This work was supported by the U.S. Army Corps of Engineers (Baltimore District), U.S. Geological Survey (Patuxent Wildlife Research Center), the Service's Chesapeake Bay Field Office, and the Maryland Environmental Service. The use of trade, product, or firm names in this publication is for descriptive purposes only and does not imply endorsement by the U.S. Government. Supporting data is located at doi.org/10.5066/ P9ZKCA0R.

\section{References}

Arnold, J.M., J. Hatch and I.C. Nisbet. 2006. Effects of egg size, parental quality and hatch-date on growth and survival of Common Tern Sterna hirundo chicks. Ibis 148:98-105.

Arnold, J.M., I.C. Nisbet and R. Veit. 2011. Assessing aural and visual cueing as tools for seabird management. The Journal of Wildlife Management 75:495-500.

Berggren, A. 2006. Intraspecific adoption and foster feeding of fledglings in the North Island robin. New Zealand Journal of Ecology 30:209-217.

Burger, J. and M. Gochfeld. 1991. The Common Tern: its breeding biology and social behavior. iUniverse.

Friesen, M.R., J.R. Beggs and A.C. Gaskett. 2017. Sensory-based conservation of seabirds: A review of management strategies and animal behaviours that facilitate success. Biological Reviews 92:1769-1784.

Jeffries, D.S. and D.H. Brunton. 2001. Attracting endangered species to "safe" habitats: Responses of fairy terns to decoys. Animal Conservation 4:301-305.

Jia, Q., X. Wang, Y. Zhang, L. Cao and A.D. Fox. 2018. Drivers of waterbird communities and their declines on Yangtze River floodplain lakes. Biological Conservation 218:240-246.

Jorgensen, J.G. and M. Bomberger Brown. 2015. Evaluating recreationists' awareness and attitudes toward Piping Plovers (Charadrius melodus) at Lake McConaughy, Nebraska, USA. Human Dimensions of Wildlife 20:367-380.
Hartman, C.A., J.T. Ackerman, M.P. Herzog, Y. Wang and C. Strong. 2018. Evaluation of social attraction measures to establish Forster's tern (Sterna forsteri) nesting colonies for the South Bay Salt Pond Restoration Project, San Francisco Bay, California-2017 Annual Report (No. 2018-1090). US Geological Survey.

Hays, H. and M. LeCroy. 1971. Field criteria for determining incubation stage in eggs of the Common Tern. The Wilson Bulletin 83:425-429.

Leumas, C.M. 2010. Understanding the use of barrier islands as nesting habitat for Louisiana birds of concern. Master's thesis, Louisiana State University.

Marcus, J.F., J.J. Dinan, R.J. Johnson, E.E. Blankenship and J.L. Lackey. 2007. Directing nest site selection of Least Terns and Piping Plovers. Waterbirds 30:251-258.

Mayo, T.W., P.W. Paton and P.V. August. 2015. Responses of birds to humans at a coastal barrier beach: Napatree Point, Rhode Island. Northeastern Naturalist 22:501-512.

Neuman, K.K., G.W. Page, L.E. Stenzel, J.C. Warriner and J.S. Warriner. 2004. Effect of mammalian predator management on Snowy Plover breeding success. Waterbirds 27:257-263.

Pochop, P.A., R.J. Johnson, D.A. Aguero and K.M. Eskridge. 1990. The status of lines in bird damage control-a review. Proceedings of the 14th Vertebrate Pest Conference. Sacramento, CA: UC Davis.

Prosser, D.J. 2017. Post phase I dike construction faunal component surveys of the Paul S. Sarbanes ecosystem restoration project at Poplar Island: the 2017 assessment of waterbird nesting. U.S. Geological Survey Patuxent Wildlife Research Center. In Press.

Rattner, B.A., R.S. Lazarus, G.H. Heinz, N.K. Karouna-Renier, and R.C. Hale. 2011. Apparent tolerance of Common Tern (Sterna hirundo) embryos to a pentabrominated diphenyl ether mixture (DE-71). U.S. Geological Survey-Patuxent Wildlife Research Center, Beltsville, MD.

Roby, D.D., K. Collis, D.E. Lyons, D.P. Craig, J.Y. Adkins, A.M. Myers and R.M. Suryan. 2002. Effects of colony relocation on diet and productivity of Caspian terns. The Journal of Wildlife Management 66:662-673.

Sawyer, L.S. and S.R. Fogle. 2013. Establishment of a new breeding colony of Australasian gannets (Morus serrator) at Young Nick's Head Peninsula. Notornis 60:180-182.

Stocking, J.J., T.R. Simons, A.W. Parsons and A.F. O'Connell Jr. 2017. Managing native predators: Evidence from a partial removal of raccoons (Procyon lotor) on the Outer Banks of North Carolina, USA. Waterbirds 40:10-18.

U.S. Army Corps Engineers/Maryland Port Administration. 2005. Final general re-evaluation report and supplemental environmental impact statement for Poplar Island Environmental Restoration Project. U.S. Army Corps of Engineers, Baltimore District, and the Maryland Port Administration.

Wetlands International. 2018. Waterbird population estimates. Wetlands International, Wageningen, The Netherlands. Available from wpe.wetlands.org (accessed January 2018).

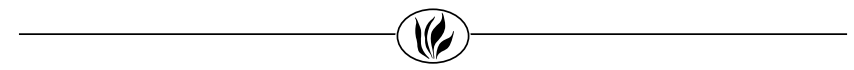

